\title{
Oxidative effects of extremely low frequency magnetic field and radio frequency radiation on testes tissues of diabetic and healthy rats
}

\author{
Kuzay D ${ }^{1}$, Ozer $C^{2}$, Sirav B ${ }^{3}$, Canseven $\mathrm{AG}^{3}$, Seyhan $\mathrm{N}^{3}$ \\ Department of Biophysics, Faculty of Medicine, Gazi University, Ankara, Turkey. \\ bahriyes76@gmail.com
}

\begin{abstract}
With the development of technology, people are increasingly under the exposure of electromagnetic fields. Individuals with chronic diseases such as diabetes are now long-term exposed to Radio Frequency-RF radiation and extremely low frequency (ELF) magnetic fields (MFs). The purpose of this present study is to investigate oxidative effects and antioxidant parameters of ELF MFs and RF radiation on testis tissue in diabetic and healthy rats. Wistar male rats were divided into 10 groups. Intraperitoneal single dose STZ $(65 \mathrm{mg} / \mathrm{kg})$ dissolved in citrate buffer $(0.1 \mathrm{M}$ ( $\mathrm{pH}$ 4.5)) was injected to diabetes groups. ELF MFs and RF radiation were used as an electromagnetic exposure for $20 \mathrm{~min} /$ day, 5 days/week for one month. Testis tissue oxidant malondialdehyde (MDA), and antioxidants glutathione (GSH), and total nitric oxide (NOx) levels were determined. The results of ANOVA and Mann-Whitney tests were compared; $p<0.05$ was considered significant. ELF and RF radiation resulted in an increase in testicular tissue MDA and NO levels $(p<0.05)$, and caused a decrease in GSH levels $(p<0.05)$ in both healthy and diabetic rats, yet more distinctively in diabetic rats. The most pronounced effect was recorded in D-RF + ELF group $(p<0.005)$. Both radiation practices increased the oxidative stress in testis tissue while causing a decrease in antioxidant level which was more distinctive in diabetic rats (Tab. 1, Fig. 3, Ref. 30). Text in PDF www.elis.sk. KEYWORDS: ELF magnetic field, RF radiation, testes, oxidative effect, rat, diabetes mellitus.
\end{abstract}

\section{Introduction}

Radio Frequency $(\mathrm{RF})$ radiation sources, which we are more intensely exposed to with the increase in the use of mobile phones and base stations, are also used in medical systems such as diathermy and MRI units for treatment purposes. Extremely low frequency (ELF) fields are becoming more common in our lives due to electrical appliances at our homes, transformers and high-tension lines. ELF electromagnetic fields (EMF) varies in the 0-300 $\mathrm{Hz}$ range. In the general population, healthy and chronically sick people are being exposed to ELF magnetic fields (MFs) and RF radiation with increasing demand of electricity and usage of mobile phones and related base stations.

${ }^{1}$ Ahi Evran University, Faculty of Medicine, Department of Physiology, Kirsehir, Turkey, ${ }^{2}$ Gazi University, Faculty of Medicine, Department of Physiology, Ankara, Turkey, and ${ }^{3}$ Gazi University, Faculty of Medicine, Department of Biophysics \& Gazi Non-Ionizing Radiation Protection Center, Ankara, Turkey

Address for correspondence: B. Sirav, Dr, Department of Biophysics, Faculty of Medicine, Gazi University, 06510 Ankara, Turkey.

Phone: +90.31220268941 , Fax: +90.3122129023

Acknowledgements: The authors thank the staff of the Gazi University Laboratory Animals and Experimental Researches Center. Electromagnetic field measurement devices used in this study were supplied by the grant from Gazi University Research Foundation, No. 31/2002-07. This study was supported by the grant from Gazi University Research Foundation, No. 01/2011-18. All animal rights were observed.
In laboratory studies made on humans, it has been observed that ELF electromagnetic fields cause abnormalities in blood chemistry and hematology, affect secretions in the neuroendocrine and digestive system, blood pressure and ECG potentials in the cardiovascular system, cause behavioral changes, and increase DNA synthesis in fibroblasts (1). Davis et al explained that the increase in cancer, other than lung cancer, is so great in recent years (2). Epidemiological studies and many laboratory investigations have suggested a link between ELF-MFs and cancer, especially childhood leukemia. ELF-MFs have been classified as a "possible human carcinogen" by International Agency for Research on Cancer-IARC (3). In a study by Jelenkovic et al, adult male Wistar rats were continuously exposed to ELF-MFs, and their dissected brains were analyzed regionally for markers of oxidative stress. Levels of super oxide dismutase (SOD) activity, NO and lipid peroxidation were significantly increased in a regional manner. SOD was increased in all regions, but the most harmful effect, namely lipid peroxidation, was seen only in the frontal cortex and basal forebrain (4). There are also many oxidative stress studies related with ELF-MFs in the liver, lung, kidney, and testis (5).

There are numerous studies indicating that RF fields cause various biological effects such as various cancer types, leukemia and lymphoma, increase in blood-brain barrier permeability, increase in brain temperature, cell and DNA synthesis, decrease in reproduction, chromosome abnormalities, increase in electrical activities of the brain and blood pressure, behavioral disorders, and learn- 
ing disabilities in children (1). Recently, many experiments have also been performed to investigate the possible oxidative damages of $\mathrm{RF}$ radiation on different body organs, including reproductive organs (6-8). Dasdag et al examined testes of rats after exposure to $900 \mathrm{MHz}$ RF radiation $(0.141 \mathrm{~W} / \mathrm{kg}, 2 \mathrm{~h} /$ day for $1 \mathrm{month})$. They did not observe any significant effects on sperm number and morphology. In another study, Dasdag et al exposed the testes of rats to $900 \mathrm{MHz}$ RF radiation with an exposure condition of SAR $0.52 \mathrm{~W} / \mathrm{kg}$ for $20 \mathrm{~min} /$ day for $1 \mathrm{month}$. They again found no significant differences in the epididymal sperm count, motility and reproductive organ weights between control and exposed groups (8). The possible biological effects of mobile phone exposure on male fertility have been extensively investigated in the past decade by many researchers. Some of them reported significant adverse effects of RF on testis and seminal parameters, including sperm motility, concentration, and morphology (9).

Scientific information on the possible biological effects of such EMF sources on individuals with diseases such as diabetes is quite insufficient. In literature, we could not find a study evaluating the effect of RF and ELF exposure while including diabetic subjects. To this end, in our study, we aimed to investigate the effects of exposure to RF radiation with an electric field of $17.25 \mathrm{~V} / \mathrm{m}$ and SAR value of $0.23 \mathrm{~W} / \mathrm{kg}$, and $50 \mathrm{~Hz}-8.2 \mathrm{mT}$ ELF-MFs on the oxidative stress and antioxidants in the testis tissue of diabetic and non-diabetic rats.

\section{Materials and methods}

\section{Experimental animals and treatments}

Sixty adult male Wistar albino rats with body weights between 220-270 g were used in the experiment. The rats were obtained from GUDAM (Gazi University Experimental Animals Center) and randomly separated into 10 groups of 6 animals each: 1) Healthy Control (C), 2) Healthy Sham (S), 3) RF Healthy (RF), 4) ELF Healthy (ELF), 5) RF + ELF Healthy (RF+ELF), 6) Diabetic Control (DC), 7) Diabetic Sham (DS), 8) Diabetic RF (D-RF), 9) Diabetic ELF (D-ELF), 10) Diabetic RF + ELF (D-RF+ELF). All animals were housed in plexiglass cages in a room with controlled temperature $\left(22^{\circ} \mathrm{C}\right)$, humidity $(50-55$ $\%$ ), and 12-hour light-dark cycle. All activities within the scope of the study were performed with the approval of the Gazi University Experimental Animal Ethics Committee under the supervision of a veterinarian and in compliance with the provisions of the Strasbourg Universal Declaration of Animal Rights of 1986. The rats were fed laboratory pellet chow and water ad libitum. Diabetic animals were defined with respect to fasting blood glucose level at the beginning of experiments. Blood glucose levels after 8 hours of fasting were first investigated and found to be normal. Then, intraperitoneal single dose STZ $65 \mathrm{mg} / \mathrm{kg}$ dissolved in citrate buffer $(0.1 \mathrm{M}(\mathrm{pH} 4.5))$ was injected to diabetes groups. Intraperitoneal single doses of citrate buffer were injected to control groups (10). After 48 hours, their fasting blood glucose levels were measured again and animals with fasting blood glucose level of $250 \mathrm{mg} / \mathrm{dl}$ or above were assumed to be diabetic animals. The rats were being checked for their diabetic state during the whole study period.
Some diabetic animals could not be used in experiments due to a change in their diabetic status, being resistant in diabetes, etc. The experiment was performed after a stabilization period (4 weeks) of the diabetic groups. None of the healthy or diabetic animals died during the experiment. ELF-MFs groups were exposed to a $50 \mathrm{~Hz}$ ELF-MFs for $20 \mathrm{~min} /$ day, 5 days per week for one month. RF groups were exposed to $2100 \mathrm{MHz}$ GSM-modulated RF radiation for 20 $\mathrm{min}$ /day, 5 days/week for one month. Both RF+ELF-MFs groups received both exposures simultaneously for $20 \mathrm{~min} /$ day, 5 days/week for one month. Rats of the healthy and diabetic cage-control groups were housed in their home cages during the entire experimental period without being subjected to any experimental manipulation. Sham groups were subjected to the same exposure procedures in the exposure systems without EMF exposures. The rats were sacrificed by decapitation after anesthesia by intramuscular injection of ketamine $(50 \mathrm{mg} / \mathrm{kg})$ and xylazine $(5 \mathrm{mg} / \mathrm{kg})$ at the end of the last exposure of the experiment, testicular tissues were removed, frozen in liquid nitrogen, and kept at $-80^{\circ} \mathrm{C}$ until biochemical analyses.

\section{Exposure systems}

ELF-MFs system developed in Biophysics laboratory has been described in detail previously (11). MFs at the center of the exposure system was measured with an EFA 300 Electromagnetic Field Analyzer (Narda, Germany). The ambient geomagnetic field was recorded as $0.02 \mathrm{mT}$. A vector signal generator (Rohde \& Schwartz, SMBV100A, Germany) was used to create RF radiation in the experimental setup. An ETS Lindgren horn antenna (ETS Lindgren, Model 3164-03, USA) was used to emit RF radiation from the generator. Polymethyl methacrylate plastic cage $(15 \times 20 \times 20 \mathrm{~cm})$ which the rats were housed in was placed symmetrically along the axis which is perpendicular and $5 \mathrm{~cm}$ below the mid-line of the horn antenna. The cage was constantly aerated to avoid the possibility of any increase in temperature inside the cage. A cage was placed in the near field of the antenna to obtain sufficient field intensity. Applied RF radiation was measured with an EMR 300 (Narda, Germany) with an electric field probe type 8.3. For RF fields; the root mean square value of electric field $\left(\mathrm{E}_{\mathrm{RMS}}\right)$ was found to be $17.25 \mathrm{~V} / \mathrm{m}$. RF environmental background level was around $0.21 \mathrm{~V} / \mathrm{m}$. SAR was calculated with the following equation: $\mathrm{SAR}=\sigma / \rho\left[\mathrm{E}_{\mathrm{RMS}}{ }^{2}\right][\mathrm{W} / \mathrm{kg}]$ where (12-13) $\mathrm{E}_{\mathrm{RMS}}$ is the root mean square value of the electric field $(\mathrm{V} / \mathrm{m}), \sigma$ is the mean electrical conductivity of the tissues in Siemens $/$ meter $(\mathrm{S} / \mathrm{m})$ and $\rho$ is the mass density $\left(\mathrm{kg} / \mathrm{m}^{3}\right)(14-15)$. Conductivity $(0.87 \mathrm{~S} / \mathrm{m})$ and mass density $\left(1105 \mathrm{~kg} / \mathrm{m}^{3}\right)$ were derived for the equivalent tissue by using dielectric properties and mass densities of these tissues. RF exposure in the experiment resulted in a whole-body average $\mathrm{SAR}$ of $0.23 \mathrm{~W} / \mathrm{kg}$ with an $\mathrm{E}_{\mathrm{RMS}}$ field of $17.25 \mathrm{~V} / \mathrm{m}$. This SAR value could be accepted as non-thermal SAR level for RF radiation, because it is known that $4 \mathrm{~W} / \mathrm{kg}$ SAR leads to $1{ }^{\circ} \mathrm{C}$ increase in the temperature of the exposed tissue.

Body temperature of rats was recorded by rectal measurements prior and after exposure sessions. Neither exposure resulted in any rectal temperature increase. During ELF-MFs exposure, only ELFMFs system was used, while during RF exposure, only RF exposure system was used. In ELF + RF exposed groups, firstly, ELFMFs exposure was activated, then RF exposures were performed. 


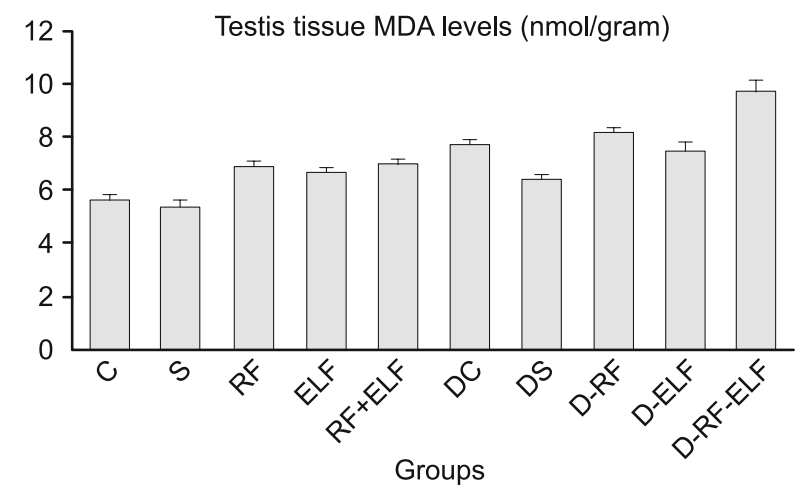

Fig. 1. Testis tissue MDA levels. The values are means $\pm \mathrm{SE}, \mathrm{p}<0.05$ : DC/D-RF, DS/D-ELF, DC/DS, p < 0.005: C/RF, C/ELF, C/RF+ELF, C/ DC, S/RF, S/ELF, S/RF+ELF, S/DS, RF/D-RF, RF+ELF/D-RF+ELF, DC/D-RF+ELF，DS/DRF，DS/D-RF+ELF，D-RF/D-RF+ELF，DELF/D-RF+ELF.

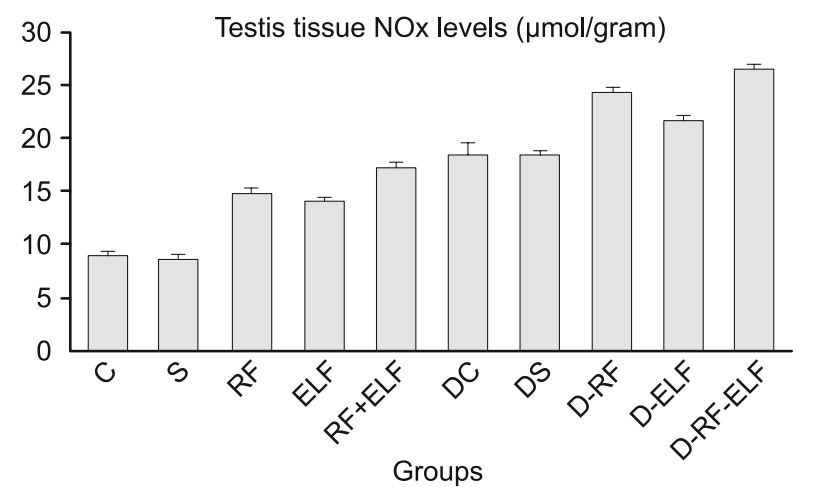

Fig. 2. Testis tissue $\mathrm{NO}_{\mathrm{x}}$ levels. The values are means $\pm \mathrm{SE} ; \mathrm{p}<0.05$ : D-RF/ D-RF+ELF, p < 0.01: RF/RF+ELF, DC/D-RF, RF/ELF, D-RF/DELF, p < 0.005: C/RF, C/ELF; C/RF+ELF, C/DC, S/RF, S/ELF, S/ RF+ELF, S/DS, ELF/RF+ELF, RF+ELF/ D-RF+ELF, DC/ D-RF+ELF, DS/D-RF, DS/D-ELF, DS/ D-RF+ELF, D-ELF/ D-RF+ELF.

\section{Measurement of tissue lipid peroxidation and GSH levels}

Lipid peroxidation was quantified by measuring the formation of thiobarbituric acid reactive substances (TBARS) (16). Samples were homogenized in ice-cold trichloroacetic acid (1 g tissue in $10 \mathrm{ml} \mathrm{10 \%} \mathrm{trichloroacetic} \mathrm{acid)} \mathrm{using} \mathrm{a} \mathrm{tissue} \mathrm{homog-}$ enizer (Heideloph Diax 900, Germany). Following centrifugation of the homogenate at $3000 \times g$ for 10 min (Hermle Z 323 K, Germany), $750 \mu$ of the supernatant was added to an equal volume of $0.67 \%(\mathrm{~m} / \mathrm{v})$ thiobarbituric acid and heated at $100{ }^{\circ} \mathrm{C}$ for 15 $\min$. The absorbance of the samples was measured at $535 \mathrm{~nm}$ using a spectrophotometer. Lipid peroxide levels are expressed in terms of MDA equivalents using an extinction coefficient of 1.56 $\times 105 \mathrm{l} \cdot \mathrm{mol}^{-1} \cdot \mathrm{cm}^{-1}$.

GSH levels were determined by the Ellman method with some modifications (17). Briefly, after centrifugation of the homogenates at $3000 \times g$ for $10 \mathrm{~min}, 0.5 \mathrm{ml}$ of the supernatant was added to $2 \mathrm{ml}$ of $0.3 \mathrm{M} \mathrm{Na}_{2} \mathrm{HPO}_{4} \cdot 2 \mathrm{H}_{2} \mathrm{O}$ solution. A $0.2 \mathrm{ml}$ solution of dithiobisnitrobenzoate $(0.4 \mathrm{mg} / \mathrm{ml} 1 \%$ sodium citrate $)$ was added and after mixing, the absorbance at $412 \mathrm{~nm}$ was measured

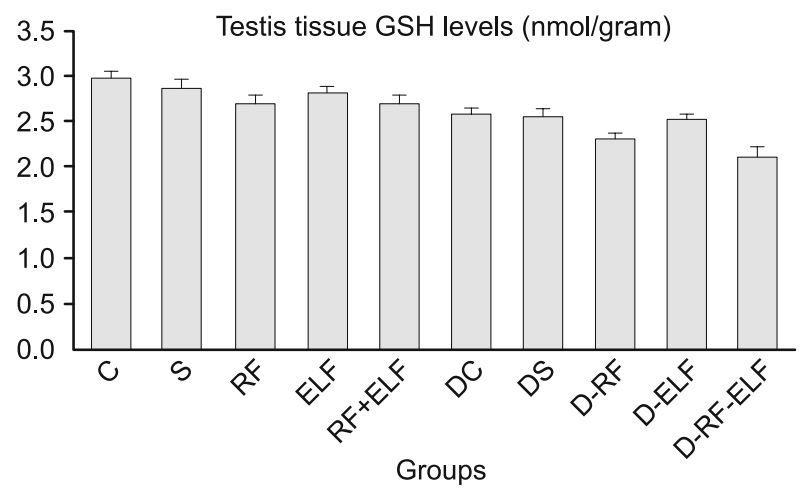

Fig. 3. Testis tissue GSH levels. The values are means $\pm \mathrm{SE}, \mathrm{p}<\mathbf{0 . 0 5}$ : C/RF+ELF, S/DS, DC/D-RF, D-RF/D-ELF, C/RF, ELF/D-ELF, DC/ D-RF+ELF, DS/D-RF, DS/ D-RF+ELF, D-ELF/ D-RF+ELF, p < 0.01: C/DC, RF+ELF/ D-RF+ELF, p $<0.005:$ S/RF, S/RF+ELF, RF/D-RF.

using a spectrophotometer (UV 1208, Shimadsu, Japan) at room temperature immediately. The GSH levels were calculated using an extinction coefficient of $13600 \mathrm{l} \cdot \mathrm{mol}^{-1} \cdot \mathrm{cm}^{-1}$.

\section{Determination of NOx (Griess assay)}

$\mathrm{NO}_{\mathrm{x}}$ levels were obtained from an Elisa reader using vanadium III chloride $\left(\mathrm{VCl}_{3}\right) / \mathrm{Griess}$ assay. Tissues were homogenized in five volumes of phosphate buffer saline $(\mathrm{pH}=7)$ and centrifuged at $2000 \times g$ for $5 \mathrm{~min}$. After centrifugation, $0.25 \mathrm{ml}$ of $0.3 \mathrm{M} \mathrm{NaOH}$ was added to $0.5 \mathrm{ml}$ of the supernatant. Incubation of the samples for $5 \mathrm{~min}$ at room temperature was followed by addition of $0.25 \mathrm{ml}$ of $5 \%(\mathrm{w} / \mathrm{v}) \mathrm{ZnSO}_{4}$ for deproteinization. This mixture was then centrifuged at $3000 \times g$ for $20 \mathrm{~min}$ and the supernatant was used for the assay. Nitrate standard solution was serially diluted and the plates were loaded with samples $(100 \mu \mathrm{l})$. Then $\mathrm{VCl}_{3}(100 \mu \mathrm{l})$, Griess reagents sulphanilamide (SULF) $(50 \mu l)$ and N-(1-naphthyl) ethylenediamine dihydrochloride (NEDD) $(50 \mu \mathrm{l})$ were added to each well. After incubation at $37{ }^{\circ} \mathrm{C}$ for $45 \mathrm{~min}$, samples were measured at $540 \mathrm{~nm}$ using an ELISA reader (18).

\section{Statistical analysis}

All data were presented as mean $\pm \mathrm{SD}$. Differences among three groups were analyzed by two-way analysis of variance (ANOVA).

Tab. 1. Mean testicular tissue levels of MDA, total NO, and GSH in all groups.

\begin{tabular}{lccc}
\hline Group & $\begin{array}{c}\text { MDA } \\
(\mathrm{nmol} / \mathrm{g})\end{array}$ & $\begin{array}{c}\mathrm{NOx} \\
(\mathrm{mmol} / \mathrm{g})\end{array}$ & $\begin{array}{c}\mathrm{GSH} \\
(\mathrm{nmol} / \mathrm{g})\end{array}$ \\
\hline Healthy Control ( C) & $5.71 \pm 0.15$ & $9.31 \pm 0.13$ & $3.02 \pm 0.08$ \\
Healthy Sham ( S ) & $5.39 \pm 0.29$ & $9.05 \pm 0.15$ & $2.91 \pm 0.09$ \\
Healthy RF ( RF ) & $6.93 \pm 0.20$ & $15.24 \pm 0.27$ & $2.73 \pm 0.08$ \\
Healthy ELF-MFs (ELF ) & $6.72 \pm 0.12$ & $14.31 \pm 0.23$ & $2.84 \pm 0.04$ \\
Healthy RF+ELF-MFs ( RF+ELF ) & $7.01 \pm 0.19$ & $17.58 \pm 0.47$ & $2.73 \pm 0.09$ \\
Diabetic Control ( DC ) & $7.53 \pm 0.19$ & $18.88 \pm 0.99$ & $2.58 \pm 0.08$ \\
Diabetic Sham ( DS ) & $6.52 \pm 0.11$ & $18.74 \pm 0.20$ & $2.58 \pm 0.07$ \\
Diabetic RF ( D- RF) & $8.25 \pm 0.13$ & $24.66 \pm 0.68$ & $2.34 \pm 0.04$ \\
Diabetic ELF-MFs ( D - ELF ) & $7.53 \pm 0.31$ & $22.09 \pm 0.36$ & $2.55 \pm 0.09$ \\
Diabetic RF+ELF-MFs (D-RF+ELF) & $9.90 \pm 0.31$ & $26.97 \pm 0.50$ & $2.15 \pm 0.11$ \\
\hline
\end{tabular}

The values are means $\pm S E ; n=6$ for each group. 
Mann-Whitney U test was used for pairwise comparisons among groups. The accepted level of significance was set at $\mathrm{p}<0.05$. Data were analyzed with statistical package (SPSS) version 13.0.

\section{Results}

When compared with the Control and Sham groups, testis tissue MDA and NOx levels showed an increase with both radiation practices in both healthy and diabetic groups. Conversely, it was found out that in both groups, antioxidant GSH decreased ( $\mathrm{p}<$ 0.05) (Figs 1, 2, 3) (Tab. 1).

Diabetes mellitus alone changes the oxidative parameters of animals. Healthy and diabetic control groups and healthy and diabetic sham groups were also found to be significantly different when compared to each other. The highest levels of oxidative parameters and the lowest antioxidant levels were seen in the diabetic RF+ELF-MFs exposed group $(\mathrm{p}<0.005)$.

\section{Discussion}

In our study, diabetic and healthy male rats were exposed to 2 different types of radiation, ELF-MFs and RF radiation. In healthy rats, exposure to $50 \mathrm{~Hz}-8.2 \mathrm{mT}$ ELF magnetic field resulted in an increase in testis tissue MDA and NOx levels and a decrease in GSH levels. In literature, there are only a few studies performing $50 \mathrm{~Hz}$ ELF-MFs. Those studies support ours in terms of their conclusions indicating that $50 \mathrm{~Hz}$ ELF-MFs adversely affects the reproductive system. De Vita Re et al reported that exposure to 50 $\mathrm{Hz}-1.7$ mT ELF-MFs for 4 hours/day for 28 days caused a significant decrease in rat spermatids (19). Seyhan and Güler used $50 \mathrm{~Hz}$, $1.35 \mathrm{kV} / \mathrm{m}$ on guinea pigs for 8 hours a day for exposure periods of 1, 3, 5, 7 and 10 days and observed kidney, lung and liver tissue and plasma MDA and SOD levels doubled on the 3rd, 5th and 7th days, while on the 10th day of the study, the increase almost tripled (20). These studies indicate that the adverse effects on biological systems may change according to the period and dose of exposure.

In our study, we observed an increase in testis tissue MDA and NOx levels and a decrease in GSH levels in both healthy and diabetic rats following exposure to RF radiation with frequency of $2100 \mathrm{MHz}$, electric field intensity of $17.25 \mathrm{~V} / \mathrm{m}$ and SAR value of $0.23 \mathrm{~W} / \mathrm{kg}$ for $20 \mathrm{~min} / 5 \mathrm{days} / 1$ week for a period of one month. In literature, it is stated that exposure to RF radiation increases oxidative stress and decreases antioxidant capacity in testes as correlated with the duration of exposure. Milankot et al stated that GSH levels decreased and lipid peroxidation increased in testis of rats that were exposed to $0.9 / 1.8 \mathrm{GHz}$ radiation for 1 hour a day for a period of 28 days (21). In another study, neonatal rats were exposed to $2.45 \mathrm{GHz}$ (Wi-Fi), $900 \mathrm{MHz}$ and $1800 \mathrm{MHz}$ (mobile phone) for 60 minutes a day for a period of 6 weeks and at the end of the 4th, 5th and 6th weeks, kidney and testis tissue samples showed a decrease in GSH, glutathione peroxidase and total antioxidant capacity, and an increase in lipid peroxidation (22). Similar results of these studies support our findings.

Tas et al exposed rats to $900 \mathrm{MHz}$ radiation for 3 hours/day for a period of 1 year, they observed that spermatogenesis decreased significantly and tunica albuginea became significantly thinner. They also stated that the weights of testis, epididymis, prostate and vesiculoseminalis did not change, and there was not a statistically significant difference in sperm concentration and motility (23). Again, in another study, following the exposure of $1900 \mathrm{MHz}$ RF radiation for 60 minutes/day for a period of 14 days, expansion in seminiferous tubule, karyomegaly in some spermatogenic nuclei and degeneration of non-spermatozoa seminiferous tubules were observed (24). Mailankot et al exposed rats to radiation of $0.9 / 1.8$ $\mathrm{GHz}$ (GSM) for 1 hour/day for a period of 28 days; they could not observe any differences between the control group and the practice group in terms of total sperm count while they found out a 40 $\%$ decrease in the number of mature sperm count in the practice group (21). Although our study did not involve a direct research into the parameters indicating abnormalities in testis functions, the increase in oxidative stress and the decrease in antioxidant level as a result of ELF-MFs and RF exposure are parallel with literature and this indirectly makes us think that the testis functions are adversely affected. Studies focused directly on testis functions in literature support this opinion of ours.

Increased oxidative stress and decreased antioxidant capacity are held responsible for most of the complications of diabetes, a metabolic disorder with an increasingly high prevalence today. Free radicals interacting with lipids, proteins and nucleic acids cause a loss in the integrity of membranes, structural and functional changes in proteins and genetic mutations (25-26). Rambir Singh et al reported an increase in testis tissue MDA levels and a decrease in SOD, CAT, GP , glutathione-S-transferase (GST), Glutathione Reductase (GR), GSH and protein levels in rats with i.p. $75 \mathrm{mg} / \mathrm{kg} \mathrm{STZ}$ induced diabetes (27). Zhao et al determined an increase in the apoptotic cell count and a decrease in SOD, TSH and LH in the testis tissue of rats 2 months after the onset of diabetes (28). In another study, it was reported that LH and FSH decreased, and this decrease was more than $50 \%$ in serum testosterone in 12-week diabetic rats (29). In another study with diabetic rats, serum testosterone levels decreased when compared to the control group on the 7th and 14th days, yet more significantly on the 14th day following STZ injection, MDA levels increased from the 5th day, and SOD, catalase and GPX levels rapidly decreased from specifically the 14th day (30). In our study, we found out an increase in MDA and NOx levels and a decrease in GSH levels in testis tissues of diabetic rats when compared to the control group. We observed these changes in diabetic subjects when compared not only to the healthy control groups, but also to RF and ELF-MFs exposed groups. These findings make us think that diabetes alone causes oxidative stress in tissue, while EMF exposure increases the tendency of oxidative effects. In literature, we could not find any studies examining the effects of RF or ELF-MFs exposure on any tissue in diabetics. For this reason, the data we obtained following the radiation exposure of our diabetic subjects are important in terms of being the results of the first study performed in this field.

In our study, exposure of rats to both RF and ELF radiation caused an increase in testis tissue MDA and NOx levels and a decrease in GSH levels. The most significant effect was observed in the group that was both diabetic and exposed to RF and ELF 
radiation. This conclusion shows us that diabetic subjects are more adversely affected by radiation when compared to healthy subjects. The data in our study and literature studies indicate that more extensive studies explaining the effects of ELF and RF radiation on the reproductive system especially of highly susceptible diabetic individuals are required.

\section{References}

1. Seyhan N. Electromagnetic pollution and our health. Nöropsikiyatri arşivi 2010; 47: 158-61.

2. Davis DL, Hoel D, Fox J, Lopez A. International trends in cancer mortality in France, West Germany, Italy, Japan, England and Wales, and the USA. Lancet 1990; 336: 474-481.

3. IARC. International Agency for research on Cancer. Non-Ionizing Radiation. Part 1, Static and Extremely Low Frequency (ELF) Electric and Magnetic Fields. Vol 80, 2000; Lyon.

4. Jelenković A, Janać B, Pesić V, Jovanović DM, Vasiljević I, Prolić Z. Effects of extremely low-frequency magnetic field in the brain of rats. Brain Res Bulletin 2006; 68: 355-360.

5. Akdag MZ, Dasdag S, Uzunlar AK, Ulukaya E, Oral AY, Çelik $N$ et al. Can safe and long-term exposure to extremely low frequency $(50 \mathrm{~Hz}) \mathrm{mag}$ netic fields affect apoptosis, reproduction, and oxidative stress? Int J Radiat Biol 2013; 89 (12): 1053-1060.

6. Erogul O, Oztas E, Yildirim I, Kir T, Aydur E, Komesli G et al. Effects of electromagnetic radiation from a cellular phone on human sperm motility: an in vitro study. Arch Med Res 2006; 37 (7): 840-843.

7. Dasdag S, Ketani MA, Akdag Z, Ersay AR, Sari I, Demirtas OC et al. Whole-body microwave exposure emitted by cellular phones and testicular function of rats. Urol Res 1999; 27 (3): 219-223.

8. Dasdag S, Zulkuf Akdag M, Aksen F, Yilmaz F, Bashan M, Mutlu Dasdag $\mathrm{M}$ et al. Whole body exposure of rats to microwaves emitted from a cell phone does not affect the testes. Bioelectromagnetics 2003; 24 (3): 182-188.

9. Agarwal A, Desai NR, Makker K, Varghese A, Mouradi R, Sabanegh E et al. Effects of radiofrequency electromagnetic waves (RF-EMW) from cellular phones on human ejaculated semen: an in vitro pilot study. Fertil Steril 2009; 92 (4): 1318-1325.

10. Bocci V, Zanardi I, Huijberts MS, Travagli V. Diabetes and chronic oxidative stress. A perspective based on the possible usefulness of ozone therapy. Elsevier 2011; 5; 45-49.

11. Canseven, A.G., Seyhan, N. Design, installation and standardization of homogeneous magnetic field systems for experimental animals. IFMBE Proceedings, Vol. 11. Prague: IFMBE, ISSN 1727-1983. In: Hozman J, Kneppo P, editors. Proceedings of the 3rd European Medical \& Biological Engineering Conference (EMBEC 2005). Prague, Czech Republic. 2005; 2333 - 2338.

12. Dasdag S, Akdag MZ, Ulukaya E, Uzunlar AK, Yegin D. Mobile phone exposure does not induce apoptosis on spermatogenesis in rats. Arch Med Res 2008; 39(1): 40-4.

13. Esmekaya, M.A, Ozer C, Seyhan, N. 900 MHz pulse-modulated radiofrequency radiation induces oxidative stress on heart, lung, testis and liver tissues. Gen Physiol Biophys 2011; 30: 84-89.

14. ICNIRP. International Commission on Non-Ionizing Radiation Protection. Guidelines for limiting exposure to time varying electric, magnetic and electromagnetic fields (up to $300 \mathrm{GHz}$ ). Health Physics 1998; 74: 494-522.
15. IEEE/ANSI. Institute of Electrical and Electronics Engineers/American National Standards Institute. IEEE C95.1-1991: IEEE standard for safety levels with respect to human exposure to radio frequency electromagnetic fields, $3 \mathrm{kHz}$ to $300 \mathrm{GHz}$. New York: IEEE Inc. 1992; 1-76.

16. Gilbert DL. Fifty years of radical ideas. In: reactive oxygen species, Ed Chiueh C.C., Ann. N. Y. Acad. Sci 2000; 899: 1-14.

17. Aykaç G, Uysal M, Yalçin AS, Koçak-Toker N, Sivas A, Oz H. The effects of chronic ethanol ingestion on hepatic lipid peroxide, glutathione, glutathione peroxidase and glutathione transferase in rats. Toxicology 1985; 36: 71-76.

18. Miranda, K.M., Espey, M.G., Wink, D.A. A rapid, simple spectrophotometric method for simultaneous detection of nitrate and nitrite. Nitric Oxide 2001; 5 (1): 62-71.

19. De Vita R, Cavallo D, Raganella L, Eleuteri P, Grollino MG, Calugi A. Effects of $50 \mathrm{~Hz}$ magnetic fields on mouse spermatogenesis monitored by flow cytometric analysis. Bioelectromagnetics 1995; 16 (5): 330-334.

20. Nesrin SEYHAN ve Göknur GULER Review of In Vivo Static and ELF Electric Fields Studies Performed at Gazi Biophysics Department. Electromagnetic Biology and Medicine 2006: 25; 307-323.

21. Mailankot M, Kunnath AP, Jayalekshmi H, Koduru B, Valsalan R. Radio Frequency Electromagnetic Radiation (RF-EMR) from GSM (0.9/1.8GHZ) Mobile Phones Induces Oxidative Stress and Reduces Sperm Motility in Rats. Clinics (Sao Paulo) 2009; 64 (6): 561-565.

22. Özorak A, Naziroğlu M, Çelik Ö, Yüksel M, Özçelik D, Özkaya MO et al. Wi-Fi (2.45 GHz)- and mobile phone (900 and $1800 \mathrm{MHz})$-induced risks on oxidative stress and elements in kidney and testis of rats during pregnancy and the development of offspring. Springer 2013; 156 (1-3): 221-229.

23. Tas M, Dasdag S, Akdag MZ, Cirit U, Yegin K, Seker U et al. Longterm effects of $900 \mathrm{MHz}$ radiofrequency radiation emitted from mobile phone on testicular tissue and epididymal semen quality. İnforma healthcare Electromagnetic Biology and Medicine 2013. doi: 10.3109/15368378.2013.801850.

24. Abdullah Al-Damegh M. Rat testicular impairment induced by electromagnetic radiation from a conventional cellular telephone and the protective effects of the antioxidants vitamins C and E. Clinics (Sao Paulo) 2012; 67 (7): 7785-929.

25. Vincent AM, Russell JW, Low P, Feldman EL. Oxidative Stress in the Pathogenesis of Diabetic Neuropathy. Endocrine Reviews 2004; 25 : $612-628$.

26. Memisogullan R, Taysi S, Bakan E, Capoglu I. Antioxidant Status and Lipid Peroxidation in Type II Diabetes Melhtus. Cell Biochem Func 2003; 21: 291-296

27. Singh R, Bhardwaj P, Sharma P. Antioxidant and toxicological evaluation of Cassia sopherain streptozotocin-induced diabetic Wistar rats. Pharmacognosy Res 2013: 5 (4) ; 225-232.

28. Zhao Y, Zhao H, Zhai X, Dai J, Jiang X, Wang G et al. Effects of Zn deficiency, antioxidants, and low-dose radiation on diabetic oxidative damage and cell death in the testis. Informa Healthcare.Toxicology Mechanisms and Methods 2013: 23; 42-47.

29. Zhao H, Xu S, Wang Z, Li Y, Guo W, Lin C et al. Repetitive exposures to low-dose X-rays attenuate testicular apoptotic cell death in streptozotocin-induced diabetes rats. Elsevier. Toxicology Letters 2010; 92: 356-364.

30. Kyathanahalli C, Bangalore S, Hanumanthappa K, Muralidhara. Experimental diabetes-induced testicular damage in prepubertal rats. J Diabet $2014 ; 6$ : $48-59$. 